\section{Is Structural Damage Evaluation by Traditional Radiographs Still Relevant in Rheumatoid Arthritis Clinical Trials?}

\section{To the Editor:}

Suppression of progression of radiographic damage in rheumatoid arthritis (RA) is the hallmark of an effective disease-modifying antirheumatic drug (DMARD), whether a biologic or nonbiologic drug. Its assessment has been part of all pivotal clinical trials, to obtain such a claim in the product monograph. In the original US Food and Drug Administration guidance document, placebo-controlled trials of 2-5 years were suggested as the method to demonstrate inhibition of radiographic progression. Recently a draft guidance document, not yet implemented, has suggested using alternative study designs because patients cannot be maintained on placebo for more than about 12 weeks 1 ; however, it is mentioned that newer imaging techniques such as magnetic resonance imaging (MRI) and ultrasound are not yet validated. The European Medicines Agency still requires 1-year trials, or in exceptional cases 6 months can be justified by "robustness of the method or convincing clinical data" with the provision to demonstrate the maintenance of this effect for an additional 12 months ${ }^{2}$.

In earlier clinical trials, it has been observed that the amount of radiographic damage is in direct relationship to disease duration and disease activity, laboratory risk factors such as elevated acute-phase reactants [erythrocyte sedimentation rate (ESR), C-reactive protein (CRP)], and the presence of high titers of anticyclic citrullinated peptide antibodies or rheumatoid factor, and the extent of baseline radiographic structural damage ${ }^{3}$. However, owing to the variability of patient clinical and laboratory features, after 1 year of observation in clinical trials, only $40 \%$ to $50 \%$ of patients taking placebo accrue additional damage, and even smaller percentages ( $10 \%$ to $20 \%$ ) when treated with a biologic DMARD, and the mean change is extremely small in both treatment and placebo groups.

In the past few years, the profile of patients enrolled in clinical trials has changed: disease duration is shorter, disease activity is lower, levels of CRP and ESR have decreased, and baseline methotrexate doses are higher ${ }^{4}$. All these elements tend to reduce the progression of structural damage. Because of the design of current trials including early rescue, the median change in damage is often in the range of 0 points in patients either taking placebo or active drug; mean change while taking placebo is $<1.5$ points, and while taking an active $\operatorname{drug}^{5},<0.5$ points.

With the blunting of additional radiographic damage in the control/placebo groups, it has become difficult to show statistically significant reduction of structural damage by the active comparator/DMARD, especially because studies are powered to show differences in clinical responses rather than differences in radiographic outcomes. This has been observed in clinical trials of golimumab and tofacitinib ${ }^{5,6}$. The absence of a claim of inhibiting radiographic progression in the product monograph of a biologic DMARD has been used by certain reimbursement agencies or third-party payers to deny drug coverage. This decision is not acceptable for a significant number of patients for whom this medication may be the best treatment. While the treatment paradigm of RA has changed over the years, based on several national and international sets of recommendations, the regulatory requirements for the approval of new DMARD have not, including the claim of reduction of structural damage.

We experienced clinicians and trialists in the management of RA think it is time to address that issue by introducing new ways of assessing the progression of structural damage through different definitions or imaging techniques ${ }^{7}$. Clearly, highly sensitive imaging techniques must be added to complement standard radiographs, for a better assessment of new highly effective therapies after the failure of conventional DMARD. Regulatory agencies have resisted so far changing the requirements, because of a lack of longterm validation of MRI and ultrasound in assessing structural damage and correlating it with functional outcomes. Open discussion with experts in the field should be initiated.
While awaiting such validation, we suggest that if a novel DMARD fails to show statistical power in the reduction of radiographic damage because of less-than-expected progression in the placebo group, while still maintaining structural integrity as evidenced by a high proportion of radiographic nonprogressors, it should still be deemed to have all the attributes of a DMARD ${ }^{8}$.

BOULOS HARAOUI, MD, FRCPC, Associate Professor, Department of Medicine, Université de Montréal, Centre Hospitalier de l'Université de Montréal, Montreal, Quebec; JACOB KARSH, MDCM, FRCPC, Professor of Medicine, Division of Rheumatology, University of Ottawa, Department of Medicine, Ottawa Hospital, Ottawa; JANET E. POPE, MD, MPH, FRCPC, Professor, Department of Medicine, Western University, Rheumatology Division, St. Joseph's Health Care, London; J. CARTER THORNE, MD, FRCPC, Head, Division of Rheumatology, Southlake Regional Health Centre, Newmarket; EDWARD C. KEYSTONE, MD, FRCPC, Professor of Medicine, University of Toronto, Director, Rebecca MacDonald Centre for Arthritis and Autoimmune Diseases, Mount Sinai Hospital, Toronto, Ontario, Canada.

Address correspondence Dr. B. Haraoui, 1551 Ontario est, Montreal, Quebec H2L 1S6, Canada. E-mail: bharaoui@videotron.ca

\section{REFERENCES}

1. US Department of Health and Human Services. Guidance for industry. Rheumatoid arthritis: developing drug products for treatment. [Internet. Accessed August 20, 2014.] Available from: www.fda.gov/downloads/Drugs/GuidanceComplianceRegulatory Information/Guidances/UCM354468.pdf

2. European Medicines Agency. Guideline on clinical investigation of medicinal products other than NSAIDs for treatment of rheumatoid arthritis. 2011. [Internet. Accessed August 20, 2014.] Available from: www.ema.europa.eu/docs/en_GB/document_library/ Scientific_guideline/2011/12/WC500119785.pdf

3. Vastesaeger N, Xu S, Aletaha D, St Clair EW, Smolen JS. A pilot risk model for the prediction of rapid radiographic progression in rheumatoid arthritis. Rheumatology 2009;48:1114-21.

4. Rahman MU, Buchanan J, Doyle MK, Hsia EC, Gathany T, Parasuraman S, et al. Changes in patient characteristics in anti-tumour necrosis factor clinical trials for rheumatoid arthritis: results of an analysis of the literature over the past 16 years. Ann Rheum Dis 2011;70:1631-40.

5. Emery P, Fleischmann R, van der Heijde D, Keystone EC, Genovese MC, Conaghan PG, et al. The effects of golimumab on radiographic progression in rheumatoid arthritis: results of randomized studies of golimumab before methotrexate and golimumab after methotrexate. Arthritis Rheum 2011;63:1200-10.

6. van der Heijde D, Tanaka Y, Fleischmann R, Keystone E, Kremer J, Zerbini C, et al. Tofacitinib (CP-690,550) in patients with rheumatoid arthritis receiving methotrexate: twelve-month data from a twenty-four-month phase III randomized radiographic study. Arthritis Rheum 2013;65:559-70.

7. Landewe R, Strand V, van der Heijde D. From inhibition of radiographic progression to maintaining structural integrity: a methodological framework for radiographic progression in rheumatoid arthritis and psoriatic arthritis clinical trials. Ann Rheum Dis 2013;72:113-7.

8. Aletaha D, Landewe R, Karonitsch T, Bathon J, Boers M, Bombardier C, et al. Reporting of disease activity in clinical trials of patients with rheumatoid arthritis: EULAR/ACR collaborative recommendations. Arthritis Rheum 2008;59:1371-7.

J Rheumatol 2014;41:11; doi:10.3899/jrheum.140383 